\title{
THE DEGREE OF MIMETIC PROTECTION GAINED BY NEW PARTIAL MIMICS
}

\author{
HUGH A. FORD* \\ Department of Zoology, University of Edinburgh
}

Received 1.x.70

\section{InTRODUGTION}

The study of Batesian Mimicry has contributed considerably to our understanding of natural selection and the nature of the predator-prey relationship. Since the theory of Batesian Mimicry was proposed (Bates, 1862) numerous workers have inferred its existence from the presence of palatable species resembling distasteful and usually conspicuous species with which they occur. There have also been numerous experimental studies on mimicry, but because of the difficulty of observing this phenomenon in nature they have usually been carried out under unnatural conditions (Muhlmann, 1934; Brower, 1958a, b, c, 1960; Schmidt, 1958, 1960; Brower et al., 1960; Sexton, 1960; Brower and Brower, 1962; Reiskind, 1965; Brower et al., 1967; Cook et al., 1969; Morrell and Turner, 1970). Nearly all these experiments have successfully demonstrated the efficacy of the mimetic pattern in protecting the mimic.

However, far fewer experiments have investigated the processes that have led to the evolution of a near perfect resemblance between the mimic and the model. The evolution of the mimetic pattern from the originally nonmimetic form is best explained by the occurrence of a single mutation, giving some resemblance to the model, followed by the selection and fixation of modifying genes gradually perfecting the resemblance (Sheppard, 1959; Clarke and Sheppard, $1960 a, b)$.

The experiments of Schmidt, Sexton and Muhlmann (loc. cit.) in the laboratory all show that more protection is obtained by better mimics, though significant protection may also be received by poorer mimics. Studies of this type on wild predators have been few. Morrell and Turner using artificial prey and wild birds also show that poorer mimics, though less frequently eaten than non-mimetic prey, are more frequently eaten than better mimics. Brower et al. (1967) and Cook et al. (1969) found that there is sometimes underpredation of artificial mimics (painted moths) compared with non-mimetic moths.

The experiments described in this paper were aimed to study further the action of mimicry using uncaged predators with artificial prey and to investigate the effectiveness of mimics showing incomplete resemblance to the model.

\section{Materials and methods}

Artificial cylindrical " caterpillars" made from a pastry mixture (two parts lard to five parts flour) were used as prey. The pastry was coloured by mixing in liquid flavourless food-colouring (from the Scottish Colouring

\footnotetext{
* Present address: Department of Biology, University of Stirling.
} 
Co., Newington, Edinburgh). Quinine sulphate $(0.5$ per cent. by weight $)$ was used in the models; at this concentration the baits were very distasteful to people and preliminary experiments showed that birds soon learnt to avoid them. Red and blue were chosen as the initial model and non-mimetic control colour respectively for the following reasons:

1. Preliminary experiments using red, green, blue, brown and yellow prey showed that red and blue were taken in approximately equal numbers, neither being particularly popular or unpopular.

2. Both colours are fairly uncommon in the natural food of the predators, except in the berries sometimes eaten by some of the species.

3. They were both conspicuous against the predominantly brown and green background of the experimental lawn.

4. Intermediate mimics would be easily made and their value as mimics could be tentatively estimated.

Two types of mimics were used: bicoloured mimics where half was exactly the same colour as the model (red) and the other half the same as the first non-mimic; (blue) and intermediate mimics, various shades of purple. These were presented in separate experiments.

Two half-cylinders (made by cutting a whole cylinder longitudinally) were pressed together side by side to make the bicoloured prey.

The predators were suburban birds of the following species; Blackbird (Turdus merula), Song Thrush (Turdus philomelos), House Sparrow (Passer domesticus) Dunnock (Prunella modularis) and Robin (Erithacus rubecula).

Individual visits of blackbirds and thrushes were observed and each prey taken was recorded as eaten (when swallowed whole) or pecked (when picked up then dropped or when partly eaten). The total number of prey eaten and pecked was termed the number taken. (This is relevant from the point of view of the prey as a peck may or may not be fatal.) In addition, the instances where the prey was regurgitated or where only half of a bicoloured prey was eaten were recorded.

The number of prey eaten by sparrows was usually unobserved since several birds were present at one time, and so it was calculated when missing prey was replaced. Robins and dunnocks only visited the experimental area occasionally and are included with sparrows in the tables as "others" since their predation was usually unobserved. On certain days when separate records of robin and dunnock predation were made the number of prey taken rarely exceeded five and the pattern of predation was never statistically significantly different from sparrows.

The experimental area was divided into 10 squares, each 5 feet by 5 feet, and 5 baits of each colour were put in each square, except in the initial training periods when 10 of the single colour were placed in each square, and in the experiment testing for frequency dependent selection when 15 models were place in each square. The squares were divided into quarters and each bait was assigned to one of the four quarters, using random number tables.

The experimental plan, showing the sequence of presentation of the prey, is laid out in table 1 .

\section{Results}

When equal numbers of red and blue were presented together, both colours were taken in approximately equal numbers, except by male black- 
birds who showed a red preference (table 2). When quinine-flavoured red prey were introduced the numbers of red taken dropped rapidly from the first to the sixth day of presentation, till by the fifth and sixth day only a minute proportion of the prey taken were red (table 3 ).

\section{TABLE 1 \\ Experimental plan \\ Date \\ Experiment \\ Colours presented}

January 21-30

February 3-15, 17

February 18, 22, 23

February 19, 21, 24

February 25, 26

February 27-29 and

March 2-5

March 6-8, 10

March 12-15, 18

March 20

March 21-24

March 24-25

March 26-29

\section{Preliminary experiments}

Testing distasteful substance*

Testing for colour preferences*

\section{Mimicry experiments}

Training to eat red prey

Training to eat blue prey

Testing for feeding on both colours

Testing for learning to avoid model

Testing response to new "half" mimic

Testing response to new nonmimic

Testing response for greater frequency of model

Training to eat new non-mimic Testing response to good and poor mimics

Testing response to change of model and switch of role of good and poor mimics
Uncoloured prey

Red, blue, green, brown, yellow

Red

Blue

Red, blue

Distasteful red model, blue

Distasteful red, blue and red, blue

Distasteful red, blue and red, yellow and blue

Distasteful red, blue and red, blue and yellow (in ratio $3: 1: 1$ )

Purple, distasteful red

Reddish purple, bluish purple, distasteful red

Distasteful blue, reddish purple, bluish purple

* Results reported in materials and methods.

TABLE 2

Numbers of red and blue baits eaten and pecked (in brackets) by each species on February 25 and 26 when equal numbers of each were presented

\begin{tabular}{|c|c|c|c|c|c|}
\hline & & sbird & & & \\
\hline & $q$ & ot & Thrush & Others & Total \\
\hline Red & $15(3)$ & $38(0)$ & $10(0)$ & $176(38)$ & $239(41)$ \\
\hline Blue & $21(2)$ & $14(3)$ & $17(0)$ & $159(58)$ & $211(63)$ \\
\hline$\chi_{(1)}^{2}$ & 0.60 & 8.02 & 1.80 & 0.40 & 0.06 \\
\hline & $>0.1$ & $0.01-0.001$ & $>0 \cdot 1$ & $>0.1$ & $>0.1$ \\
\hline
\end{tabular}

$\chi_{(1)}^{2}$ is between numbers of red eaten and blue eaten assuming random feeding.

The bicoloured mimics were then introduced along with the red and blue prey. The results showed that again the numbers of red taken were minimal, and that significantly fewer of the bicoloured mimics were taken than the blue. In addition a greater proportion of the mimics taken were 
pecked and not eaten (table 4), and sparrows and others ate the blue half of the mimic on 44 occasions and blackbirds three times. A new blue and yellow bicoloured non-mimic was then presented along with the red and

TABLE 3

Numbers of red and blue baits eaten and pecked (in brackets) before and after introduction of quinine to the red baits

\begin{tabular}{|c|c|c|c|c|c|c|}
\hline \multicolumn{7}{|r|}{$\begin{array}{l}\% \mathrm{red} / \mathrm{blue} \\
\text { taken }\end{array}$} \\
\hline $\begin{array}{l}\text { Total of } \\
2 \text { days }\end{array}$ & $\begin{array}{l}\text { red } \\
\text { blue }\end{array}$ & $\begin{array}{l}53(3) \\
35(5)\end{array}$ & $\begin{array}{l}10(0) \\
17(0)\end{array}$ & $\begin{array}{l}176(38) \\
159(58)\end{array}$ & $\begin{array}{l}239(41) \\
211(63)\end{array}$ & 102 \\
\hline \multicolumn{7}{|c|}{ With quinine } \\
\hline Day 1 & $\begin{array}{l}\text { red } \\
\text { blue }\end{array}$ & $\begin{array}{r}6(1) \\
18(4)\end{array}$ & $\begin{array}{r}6(0) \\
12(0)\end{array}$ & $\begin{array}{l}32(25) \\
65(17)\end{array}$ & $\begin{array}{l}44(26) \\
95(21)\end{array}$ & 60 \\
\hline Day 2 & $\begin{array}{l}\text { red } \\
\text { blue }\end{array}$ & $\begin{array}{c}2(1) \\
20(10)\end{array}$ & $\begin{array}{l}2(0) \\
5(0)\end{array}$ & $\begin{array}{r}9(30) \\
133(50)\end{array}$ & $\begin{array}{r}13(31) \\
158(60)\end{array}$ & 20 \\
\hline Day 3 & $\begin{array}{l}\text { red } \\
\text { blue }\end{array}$ & $\begin{array}{r}1(1) \\
25(7)\end{array}$ & $\begin{array}{l}1(0) \\
7(0)\end{array}$ & $\begin{aligned} 6 & (14) \\
201 & (120)\end{aligned}$ & $\begin{array}{c}8(15) \\
233(127)\end{array}$ & $6 \cdot 4$ \\
\hline Day 4 & $\begin{array}{l}\text { red } \\
\text { blue }\end{array}$ & $\begin{array}{c}1(0) \\
59(16)\end{array}$ & $\begin{array}{r}0(1) \\
14(1)\end{array}$ & $\begin{array}{c}12(6) \\
191(68)\end{array}$ & $\begin{array}{c}13(7) \\
264(85)\end{array}$ & $5 \cdot 7$ \\
\hline Day 5 & $\begin{array}{l}\text { red } \\
\text { blue }\end{array}$ & $\begin{array}{r}0(2) \\
43(9)\end{array}$ & $\begin{array}{r}0(0) \\
13(0)\end{array}$ & $\begin{array}{c}1(5) \\
223(39)\end{array}$ & $\begin{array}{c}1(7) \\
279(48)\end{array}$ & $2 \cdot 4$ \\
\hline Day 6 & $\begin{array}{l}\text { red } \\
\text { blue }\end{array}$ & $\begin{array}{c}0(0) \\
92(16)\end{array}$ & $\begin{array}{c}2(0) \\
32(31)\end{array}$ & $\begin{array}{c}5(5) \\
313(25)\end{array}$ & $\begin{array}{c}7(5) \\
437(72)\end{array}$ & 4 \\
\hline
\end{tabular}

TABLE 4

Numbers of red (model), red and blue (mimic), and blue (non-mimic), eaten and pecked (in brackets) on each day of presentation. Number taken includes prey where one-half only is taken (see text)

$\begin{array}{llcrrrr} & & \text { Blackbird } & \text { Thrush } & \text { Others } & \text { Total } & \text { No. taken } \\ \text { Day 1 } & \text { red } & 0(1) & 2(0) & 0(3) & 2(4) & 6 \\ & \text { mimic } & 1(9) & 5(2) & 21(17) & 27(28) & 58 \\ & \text { blue } & 32(3) & 24(1) & 154(49) & 210(53) & 263 \\ \text { Day 2 } & \text { red } & 0(0) & 0(0) & 5(3) & 5(3) & 8 \\ & \text { mimic } & 0(2) & 1(0) & 37(33) & 38(35) & 86 \\ & \text { blue } & 71(11) & 37(3) & 254(85) & 362(99) & 461 \\ \text { Day 3 } & \text { red } & 7(2) & 0(0) & 0(3) & 7(5) & 12 \\ & \text { mimic } & 2(0) & 4(0) & 24(17) & 30(17) & 55 \\ & \text { blue } & 103(14) & 40(2) & 227(63) & 370(79) & 449 \\ \text { Day } 4 & \text { red } & 2(0) & 0(0) & 4(3) & 6(3) & 9 \\ & \text { mimic } & 1(1) & 1(1) & 40(10) & 42(12) & 65 \\ & \text { blue } & 78(19) & 30(0) & 326(83) & 434(102) & 436 \\ \text { Day 5 } & \text { red } & 0(0) & 0(0) & 4(0) & 4(0) & 4 \\ & \text { mimic } & 2(1) & 5(0) & 49(0) & 56(1) & 69 \\ & \text { blue } & 41(19) & 26(2) & 401(0) & 468(21) & 489 \\ \text { Total } & \text { red } & 9(3) & 2(0) & 13(12) & 24(15) & 39 \\ \text { of 5 } & \text { mimic } & 6(13) & 16(3) & 171(77) & 193(93) & 333 \\ \text { days } & \text { blue } & 325(66) & 157(8) & 1362(280) & 1844(354) & 2198\end{array}$

blue mimic and the red model. This would compare the predators' behaviour to a new non-mimetic bicoloured type with their behaviour to the new bicoloured mimic. Significantly more of the yellow and blue were eaten by 
all species although in the case of sparrows and others as many mimics as non-mimics were taken (a greater proportion of the former being pecked and not eaten) (table 5).

\section{TABLE 5}

Numbers of mimetic and non-mimetic prey eaten and pecked (in brackets) (including blue half only eaten) on the five days of presentation of red model, red and blue mimic, and yellow and blue non-mimic

\begin{tabular}{|c|c|c|c|c|c|}
\hline \multirow{3}{*}{ Day 1} & \multicolumn{2}{|c|}{ Blackbird } & \multirow{3}{*}{$\begin{array}{c}\text { Thrush } \\
10(4) \\
8(3)\end{array}$} & \multirow{3}{*}{$\begin{array}{l}\text { Others } \\
71(116) \\
89(68)\end{array}$} & \multirow{3}{*}{$\begin{array}{c}\text { Total } \\
87(124) \\
122(77)\end{array}$} \\
\hline & mimic & $6(4)$ & & & \\
\hline & non-mimic & $25(6)$ & & & \\
\hline \multirow[t]{2}{*}{ Day 2} & $\operatorname{mir}$ & $0(2)$ & $10(0)$ & $70(77)$ & $80(79)$ \\
\hline & nimic & $41(1)$ & $21(0)$ & $75(41)$ & $137(42)$ \\
\hline \multirow[t]{2}{*}{ Day 3} & & $10(3)$ & 9 (3) & $67(65)$ & $86(79)$ \\
\hline & imic & $52(4)$ & $23(0)$ & 129 (18) & $204(22)$ \\
\hline \multirow{2}{*}{ Day 4} & $\operatorname{mim}$ & $4(5)$ & $4(3)$ & $88(56)$ & $96(64)$ \\
\hline & non-mimic & $59(5)$ & $21(0)$ & $139(6)$ & 219 (11) \\
\hline \multirow[t]{2}{*}{ Day 5} & mimic & $4(7)$ & $11(3)$ & $152(86)$ & $167(96)$ \\
\hline & non-mimic & $118(6)$ & $28(0)$ & $216(14)$ & $362(20)$ \\
\hline \multirow[t]{2}{*}{ Total } & $\min$ & $24(21)$ & $44(13)$ & 448 & $516(434)$ \\
\hline & non-mimic & $295(22)$ & 101 & 648 & \\
\hline \multicolumn{5}{|c|}{$\chi_{(1)}^{2}$ mimic eaten $v$} & $178 \cdot 7 *$ \\
\hline \multicolumn{2}{|c|}{$\begin{array}{l}\chi_{(1)}^{2} \text { mimic taken } v . \\
\text { non-mimic taken }\end{array}$} & $204 \cdot 3 * * *$ & $13 \cdot 7 * * *$ & 1.71 & $32.7 *$ \\
\hline
\end{tabular}

Blue half only eaten by sparrows and others 258 times in mimics

and 60 times in non-mimics

by blackbirds

2 times in non-mimics

by thrushes once in both mimics and non-mimics.

*** denotes significance at $0 \cdot 1$ per cent. level.

In this experiment the frequency of mimic to model was high. It was considered that mimicry would only be effective if the mimic was relatively uncommon in relation to the model, though Brower (1960a) found that the

\section{TABLE 6}

Numbers of mimetic, red and blue, and non-mimetic, yellow and blue, prey taken with model: mimic ratios of $1: 1$ and $3: 1 . x_{(1)}^{2}$ is between mimics and non-mimics taken with the two frequencies of model assuming model frequency does not affect predation

\begin{tabular}{clcccc} 
Model/mimic & & Blackbird & Thrush & Others & Total \\
$1: 1$ & non-mimic & 295 & 101 & 567 & 963 \\
& mimic & 24 & 44 & 393 & 461 \\
$3: 1$ & non-mimic & 68 & 34 & 298 & 400 \\
\multirow{2}{*}{$\begin{array}{l}2 \\
\chi_{(1)}^{*}\end{array}$} & mimic & 2.03 & 14 & 109 & 125 \\
** denotes significance at 1 per cent. level, *** at 0.1 per cent. level.
\end{tabular}

mimic still receives some protection when it is nine times as common as the model. To test the predators' response to a lower mimic to model ratio the numbers of model were trebled. Sparrows and others ate an even greater proportion of bicoloured non-mimics than before, indicating greater avoidance of the mimic (table 6). 
Although this is significant $\left(\chi_{(1)}^{2}=23.9, \quad \mathrm{P}<0.001\right)$ it may still be accounted for by day-to-day fluctuations.

A new colour (purple) of edible prey was then presented together with the red model for four days to train the birds to accept this colour. On the last day of presentation 450 of this colour were taken, indicating the birds' acceptance of this new prey. Subsequently the purple was replaced by reddish purple and bluish purple. The reddish purple were taken far less frequently than the bluish purple by all species (table 7). The red model

TABLE 7

Numbers of red, reddish purple and bluish purple eaten and pecked (in brackets) when they were presented together in equal numbers after training on an intermediate purple prey. $\chi_{(1)}^{2}$ are calculated for numbers of reddish purple eaten to numbers of bluish purple eaten, assuming random predation

\begin{tabular}{lcccc} 
& Blackbird & Thrush & Others & Total \\
Red & $0(1)$ & $0(0)$ & $2(8)$ & $2(9)$ \\
Reddish purple & $10(6)$ & $8(3)$ & $145(35)$ & $163(44)$ \\
Bluish purple & $54(2)$ & $46(1)$ & $408(41)$ & $508(44)$ \\
$\chi_{(1)}^{2}$ & $30 \cdot 2 * * *$ & $26 \cdot 7 * * *$ & $125 \cdot 2 * * *$ & $178 \cdot 0 * * *$ \\
\multicolumn{4}{l}{ *** denotes significance at $0 \cdot 1$ per cent. level. }
\end{tabular}

was then replaced by a blue model, containing the same concentration of quinine. The bluish purple then became the better mimic and the reddish purple the poorer one. A direct comparison of the two days of red model and the four days of blue model shows that the number of bluish purple eaten by blackbird and thrush is in fact greater with the blue models, while the numbers eaten by sparrows and others is not significantly different with the two models (table 8). However, if the individual days are looked at

TABLE 8

Numbers of blue, reddish purple and bluish purple eaten and pecked (in brackets) when the distasteful blue model was presented. $\chi_{(1)}^{2}$ compares the numbers of bluish purple and reddish purple eaten with the two colours of model

\begin{tabular}{lcccc} 
& Blackbird & Thrush & Others & Total \\
Blue & $8(6)$ & $4(5)$ & $101(62)$ & $113(73)$ \\
Reddish purple & $2(3)$ & $1(0)$ & $301(58)$ & $304(61)$ \\
Bluish purple & $59(25)$ & $58(3)$ & $854(127)$ & $971(155)$ \\
$\chi_{(1)}^{2}$ & $5.47 *$ & $6.63 *$ & 0.01 & 0.05 \\
\multicolumn{4}{c}{ * denotes significance at 5 per cent. level. }
\end{tabular}

(fig. 1) the proportion of reddish purple taken by sparrows and others appears to drop from day 1 to day 2 of red model and again on the first day of blue model, then to increase on the second and third day of blue model. The difference between day 1 and day 2 of red prey and between day 2 and day 3 of blue model are both significant.

\section{Discussion}

Although the demonstration of mimicry has been frequently successful using caged predators, few studies have successfully shown it operating in 
more natural conditions with free living predators. The present study was aimed at examining the response of the predators to artificial prey under mimetic situations. The results showed rapid learning to avoid distasteful

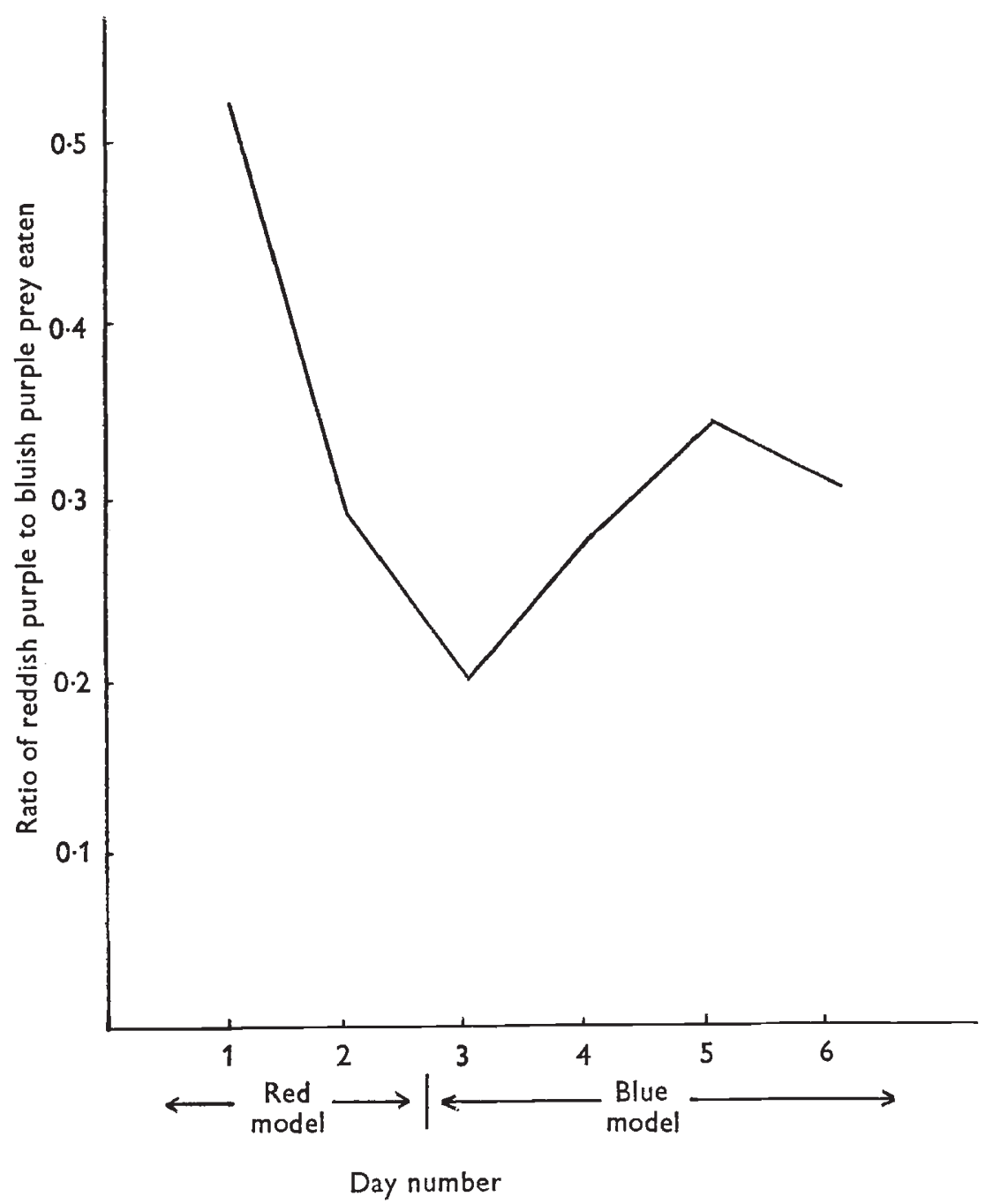

FiG. 1.-Ratio of reddish purple to bluish purple eaten with two days of red model and four days of blue model.

models and underpredation of a bicoloured partial mimic. This underpredation of the partial mimic need not necessarily be explained by its mimetic pattern. Three factors may influence the behaviour of a predator towards its potential prey:

\section{(i) Conspicuousness}

There is a strong selection in most animals for cryptic colouration, the best hidden individuals being most likely to be overlooked by predators. 
Red and blue were chosen in these experiments as they should be equally conspicuous against the lawn background. It is possible that the bicoloured prey is less conspicuous, as its pattern may be disruptive, though many warningly coloured insects are bicoloured, presumably to make them more conspicuous (e.g. wasps, ladybirds).

\section{(ii) Previous experience}

There is considerable evidence (Tinbergen, 1960; Allen (pers. comm.); Allen and Clarke, 1968; Croze, 1970) that birds develop specific search images for food items. Such search images are most likely to develop for abundant, palatable and conspicuous foods. Alternative foods may not be eaten because they are passively overlooked or they may be actively avoided. New or uncommon foods will fall into the former category, while unpalatable prey and mimics fall into the latter.

\section{(iii) Innate preferences}

Coppinger (1969) discussed innate avoidance of particular patterns and avoidance of novel stimuli. He considers that the latter may be important, and it is clearly related to the search image theory.

To clarify the nature of the response, a new mimetic type was introduced to determine how much of the avoidance of the mimic was due to its novelty. Although a higher proportion of the prey taken are mimics, suggesting that some of the previous protection was due to the mimic's novelty, more of the non-mimics than the mimics are taken, showing that at least some of the protection was due to the mimetic pattern of the red and blue prey.

Thus, even in a natural situation, one might expect a mutation, producing a new mimetic pattern, to be selected due to its novelty, in addition to any protection it might obtain from its mimetic resemblance. This may well be an important, and previously rather overlooked, factor in the early stages of the evolution of mimicry.

Increasing the frequency of the model gives increased protection to the mimic compared to the non-mimic. For mimicry to be effective the predator must experience sufficient models, to associate the particular pattern with distastefulness. If the model is rare relative to the mimic, the predator is less likely to learn to avoid it. A model to mimic ratio of $1: 1$, used in these experiments, is probably higher than usual in nature and it has even been suggested that the mimic needs to be rare in comparison with the model. The experiments of Brower (1960) with starlings and coloured mealworms showed that some protection of the mimic was received even with a model to mimic ratio of $1: 9$.

In the situations considered so far resemblance to the model has been achieved by presenting prey showing the model colour on half of the mimic. This is analagous to situations where the pattern of the mimic resembling the model is achieved by a single mutation. Alternatively mimics may show continuous variation with one extreme best resembling the model. This situation was simulated using shades of purple. The mimic most closely resembling the model was eaten less frequently than the one resembling it less well. This shows the effectiveness of mimicry of this type. In this experiment the effect of novelty was the same for both good and poor mimics since they were introduced at the same time. When the model was changed 
to blue so that the previously poor mimic was now the better one, the results were somewhat confusing; although the now better mimics do not receive more protection overall, the day-to-day changes do suggest a change in preference.

These experiments are similar to those carried out by Duncan and Sheppard (1965), who used coloured solutions and chicks. The strongest solution was associated with an electric shock, and progressively weaker solutions (poorer mimics) received more attention. When a large shock was given on drinking the model solution there was even a significant difference in the responses to the poorest mimic and the uncoloured control.

The experiments carried out in this study all point to considerable advantages gained by the partial mimics. This response of the predators is emphasised by the fact that a large proportion of the bicoloured mimics were either pecked or only partly eaten; and when they were only partly eaten it was always the blue half which was eaten. This could be analagous to an insect where only the most vulnerable parts of the body are mimetic, directing any attack to less vulnerable parts.

The experimental period was not long, and the responses of the birds may be different at different times of the year. This difference may take the form of different colour preferences, or changes in the birds' keenness to discriminate. For example, the experiments were carried out during the winter when food may have been scarce and the birds were perhaps more willing to take unusual or less attractive food. Irrespective of the precise feeding pattern it is clear that the behavioural response of the predators would give sufficient advantage to an initially poor mimic for full mimicry to evolve by gradual improvement of the resemblance.

\section{Summary}

1. The response of wild birds to artificial partial mimics was studied in a situation simulating the evolution of Batesian Mimicry.

2. The birds rapidly learnt to avoid a red prey containing quinine.

3. They showed considerable avoidance of a new bicoloured partial mimic and strongly preferred the familiar non-mimetic colour.

4. They preferred a new non-mimetic bicoloured prey to a mimetic bicoloured one. When the mimetic prey was taken it was pecked or only partly eaten far more often than the non-mimic. When partly eaten it was always the blue (nonmimetic) half which was eaten and the red (mimetic) half which was left.

5. The birds preferred a poorer mimic to a better mimic when the prey approached the model colour in shade.

6. When a new model colour was introduced changing the role of the poor and good mimic, a change in preference was suggested but not conclusively shown.

7. It was suggested that these experiments agreed with the hypothesis that mimicry evolves through a stage of imperfection. It was also suggested that the novelty of the initial mimics might afford them some perfection.

Acknowledgments. -I would like to thank Dr Bryan Glarke, Dr John Godfrey and John Allen for continual help during these experiments and for discussing the results with me, and Dr Janis Antonovics for most helpful criticism and discussion of this paper. 


\section{REFERENCES}

ALLEN, J. A. 1967. Selection by wild birds when feeding on dimorphic artificial prey. Honours Thesis, University of Edinburgh.

ALLEN, J. A., AND CLARKE, B. C. 1968. Evidence for apostatic selection in wild passerines. Nature, 220, 501-2.

Bates, H. w. 1862. Contributions to an insect fauna of the Amazon Valley Lepidoptera, Heliconiidae. Trans. Linn. Soc, London, 23, 495-566.

BROWER, J. V-z. 1958a. Experimental studies of mimicry in some North American butterflies. Part I. The Monarch (Danaus plexippus) and the Viceroy (Limenitis archippus archippus). Evolution, 12, 32-47.

BROWER, J. V-z. 1958b. Experimental studies of mimicry in some North American butterflies. Part II. Battus philenor and Papilio troilus, P. polyxenes and P. glaucus. Evolution, 12, 123-136.

BROWER, J. V-z. 1958c. Experimental studies of mimicry in some North American butterflies. Part III. Danaus gilippus berenice and Limenitis archippus floridensis. Evolution, 12, 273-285.

BROWER, J. v-z. 1960. Experimental studies of mimicry in some North American Butterflies. Part IV. The reactions of Starlings to different proportions of models and mimics. American Naturalist, 94, 271-282.

BROWER, L. P., BROWER, J. V-Z., AND WESTCOTT, P. W. 1960. Experimental studies of mimicry in some North American Butterflies. Part V. The reactions of toads (Bufo terrestris) to bumblebees (Bombus americanorum) and their robberfly mimics (Mallophora bomboides), with a discussion of aggressive mimicry. American Naturalist, 94, 343-355.

BROWER, J. V-Z., AND BROWER, L. P. 1962. Experimental studies of mimicry in some North American butterflies. Part VI. The reactions of toads (Bufo terrestris) to honeybees (Apis mellifera), and their dronefly mimics (Eristalis vinetorum). American Naturalist, 69, 297-307.

BROWER, L. P., COOK, L. M., AND CROZE, H. J. 1967. Predation responses to artificial Batesian mimics released in a neotropical environment. Evolution, 21, 11-23.

CLARKE, C. A., AND SHEPPARD, P. M. 1960a. The evolution of mimicry in the Butterfly, Papilio dardanus. Heredity, 14, 163-174.

GLARKE, C. A., AND SHEPPARD, P. M. 1960b. Supergenes and mimicry. Heredity, 14, 175-185. COOK, L. M., BROWER, L. P., AND ALCOCK, J. 1969. An attempt to verify mimetic advantage in a neotropical environment. Evolution, 23, 339-345.

COPPINGER, R. P. 1969. The effect of experience and novelty on avian feeding behaviour with reference to the evolution of warning colouration in Butterflies. Part I. Reactions of wild caught adult Blue Jays to novel insects. Behaviour, 35, 45-60.

CROZE, H. 1970. Searching image in Carrion Crows. Zeitschrift fur tier-psychologie, Beiheft $5,1-85$.

DUNCAN, C. J., AND SHEPPARD, P. M. 1965. Sensory discrimination and its role in the evolution of Batesian mimicry. Behaviour, 35, 269-282.

MORRELL, G. M., AND TURNER, J. R. G. 1970. Experiments on mimicry. I. The response of wild birds to artificial prey. Behaviour, 36, 116-130.

мüHLMANN, H. 1934. Im Modellversuch künstlich erzeugte Mimkry und ihre Bedeutüng für den "Nachahmer". Z. Morph. Okol., Tiere 28, 259-296.

REISKIND, J. 1965. Behaviour of an avian predator in an experiment simulating Batesian Mimicry. Animal Behaviour, 13, 466-469.

schмid, R. s. 1958. Behavioural evidence on the evolution of Batesian Mimicry. Animal Behaviour, 16, 149-158.

schmid, R. s. 1960 . Predator behaviour and the perfection of the incipient mimetic resemblance. Behaviour, 16, 149-158.

sexton, O. J. 1960. Experimental studies on artificial Batesian Mimics. Behaviour, 15, 244-252.

SHEPPARD, P. M. 1959. The evolution of mimicry; a problem in ecology and genetics. Cold Spring Harbor Symp. Quant. Biol., 24, 131-140.

TiNBERGEN, L. 1960. The natural control of insects in pinewoods. 1. Factors influencing the intensity of predation by songbirds. Archs. Néerl. Zool., 13, 265-343. 